Article

\title{
Biomphalaria glabrata Metallothionein: Lacking Metal Specificity of the Protein and Missing Gene Upregulation Suggest Metal Sequestration by Exchange Instead of through Selective Binding
}

\author{
Michael Niederwanger ${ }^{1}$ (D), Sara Calatayud ${ }^{2}$, Oliver Zerbe ${ }^{3}$, Sílvia Atrian ${ }^{2,+}{ }^{\dagger}$, Ricard Albalat $^{2}$ (D), \\ Mercè Capdevila ${ }^{4}$ (D) Òscar Palacios ${ }^{4}$ and Reinhard Dallinger ${ }^{1, *}$ \\ 1 Institute of Zoology and Center of Molecular Biosciences Innsbruck (CMBI), University of Innsbruck, \\ Technikerstraße 25, A-6020 Innsbruck, Austria; michael.niederwanger@uibk.ac.at \\ 2 Departament de Genètica, Microbiologia i Estadística and Institut de Recerca de la Biodiversitat (IRBio), \\ Universitat de Barcelona, Av. Diagonal 643, E-08028 Barcelona, Spain; scalatro7@alumnes.ub.edu (S.C.); \\ ralbalat@ub.edu (R.A.) \\ 3 Department of Chemistry, University of Zürich, Winterthurerstrasse 190, CH-8057 Zürich, Switzerland; \\ oliver.zerbe@chem.uzh.ch \\ 4 Departament de Química, Facultat de Ciències, Universitat Autònoma de Barcelona, \\ E-08193 Cerdanyola del Vallès, Spain; merce.capdevila@uab.cat (M.C.); oscar.palacios@uab.cat (Ò.P.) \\ * Correspondence: reinhard.dallinger@uibk.ac.at; Tel.: +43-512-5075-1861; Fax: +43-512-5075-1899 \\ $\dagger$ Deceased.
}

Received: 30 May 2017; Accepted: 1 July 2017; Published: 6 July 2017

\begin{abstract}
The wild-type metallothionein (MT) of the freshwater snail Biomphalaria glabrata and a natural allelic mutant of it in which a lysine residue was replaced by an asparagine residue, were recombinantly expressed and analyzed for their metal-binding features with respect to $\mathrm{Cd}^{2+}, \mathrm{Zn}^{2+}$ and $\mathrm{Cu}^{+}$, applying spectroscopic and mass-spectrometric methods. In addition, the upregulation of the Biomphalaria glabrata MT gene was assessed by quantitative real-time detection PCR. The two recombinant proteins revealed to be very similar in most of their metal binding features. They lacked a clear metal-binding preference for any of the three metal ions assayed-which, to this degree, is clearly unprecedented in the world of Gastropoda MTs. There were, however, slight differences in copper-binding abilities between the two allelic variants. Overall, the missing metal specificity of the two recombinant MTs goes hand in hand with lacking upregulation of the respective MT gene. This suggests that in vivo, the Biomphalaria glabrata MT may be more important for metal replacement reactions through a constitutively abundant form, rather than for metal sequestration by high binding specificity. There are indications that the MT of Biomphalaria glabrata may share its unspecific features with MTs from other freshwater snails of the Hygrophila family.
\end{abstract}

Keywords: metallothionein; metal-binding; zinc; copper; cadmium; Biomphalaria glabrata; Gastropoda; Hygrophila

\section{Introduction}

In many species of Gastropoda (snails and slugs), cadmium $(\mathrm{Cd})$ and copper $(\mathrm{Cu})$ metabolism and detoxification are apparently linked to the expression of metal-specific metallothionein (MT) isoforms. Terrestrial snails like the Roman snail (Helix pomatia) of the Stylommatophora phylum, for example, possess $\mathrm{Cd}$ and $\mathrm{Cu}$-specific $\mathrm{MT}$ genes whose transcriptional activation can be induced by metal exposure, leading to the expression of two-domain MT proteins which preferentially bind and inactivate the respective cognate metal ion [1-3]. Likewise, snails of the taxonomic 
clade of Caenogastropoda such as the marine periwinkle (Littorina littorea), possess a Cd-specific MT whose expression is strongly induced by $\mathrm{Cd}$ exposure [4] and environmental stressors [5]. I contrast to terrestrial snails from the Stylommatophora phylum, however, the MTs of Littorina littorea and other species of the Caenogastropoda clade possess three metal-binding domains [4]. Overall, the metal-binding performance of most of these MTs can be attributed to an intact domain structure with an optimized metal-binding stoichiometry, where every domain provides nine cysteine-linked sulfur atoms that coordinate with high affinity three $\mathrm{Cd}^{2+}$ or four to six $\mathrm{Cu}^{+}$ions. In accordance with the metal-specific binding preference of the expressed proteins, the respective $M T$ genes can be upregulated in response to exposure to the corresponding metal ion $[2,6]$. It has been suggested that the high binding specificity of some snail MTs for $\mathrm{Cd}^{2+}$ may serve detoxification of this harmful metal by keeping $\mathrm{Cd}^{2+}$ pathways within the snail organism strictly separated from pathways of other, essential metal ions [1].

In freshwater pulmonate snails of the Hygrophila clade, the situation may be different. Although they possess MTs [7], an important pathway of metal detoxification in these species is represented by metal-binding to phytochelatins as shown, for example, for the Great Pond snail, Lymnaea stagnalis [8]. Accordingly, the capacity of Hygrophila to express MTs in response to metal stress is apparently inhibited or strongly reduced when compared to other gastropod species, as recently demonstrated in the Bladder snail, Physa acuta [9]. Biomphalaria glabrata is another species of Hygrophila that lives in tropical and subtropical rivers and ponds, being one of the most important intermediate hosts of the trematode, Schistosoma mansoni $[10,11]$ that infects with schistosomiasis millions of people worldwide [12]. In the present study we have examined the metal-binding performance of two MT allelic variants of Biomphalaria glabrata, the wildtype form (BgwtMT) and a natural mutant in which a lysine residue has been replaced by an asparagine residue (BgKNMT). Last but not least, it was also explored how the Biomphalaria glabrata MT variants compare with structural and functional features of MTs from other Hygrophila species. In addition, the expression of the Biomphalaria glabrata MT gene was assessed under control and Cd exposure conditions.

\section{Results and Discussion}

\subsection{The BgwtMT and BgKNMT Recombinant Proteins}

The primary structure of the wildtype MT from Biomphalaria glabrata (BgwtMT) was originally obtained by translation from the nucleotide sequence of the corresponding gene (see below), and afterwards confirmed by mRNA isolation and sequencing from laboratory-grown living snails [13] (in preparation). The second sequence originates from a natural allelic MT variant with an amino acid replacement $(\mathrm{K} \rightarrow \mathrm{N})$ (BgKNMT), and was chosen from a number of different allelic mutants, all of them characterized from individuals of the same laboratory-grown population. The primary structure of the two recombinant proteins is shown in Figure 1. Due to the specific recombinant expression conditions, the two proteins contain two additional amino acid residues (GS) at their N-termini in relation to their native isoforms previously characterized [13] (in preparation). As previously shown [14], these modifications do not interfere with the metal-binding capacity of the recombinant proteins.

The mass spectra of the recombinant productions of Zn-BgwtMT and Zn-BgKNMT recorded under acidic conditions (Figure 2) allowed confirmation of the expected masses of both proteins according to their sequences. 


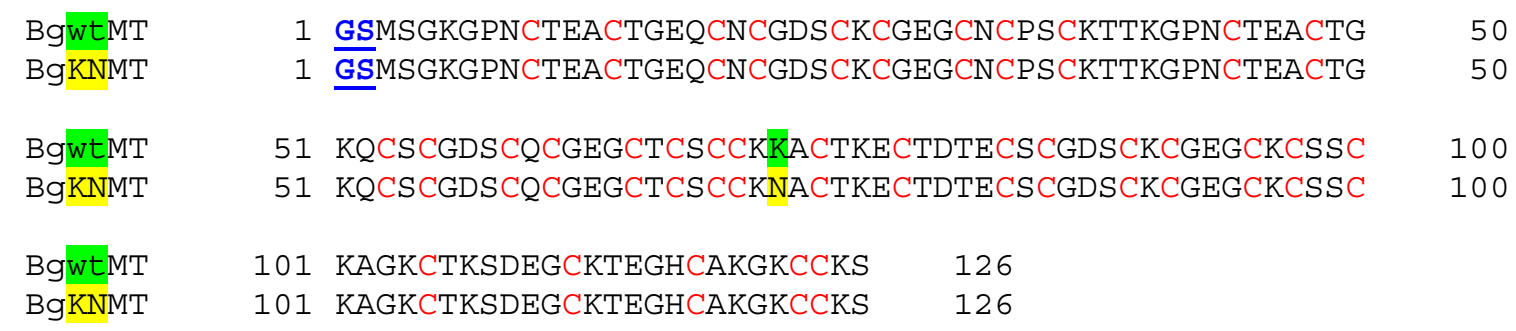

Figure 1. Amino acid sequences of the studied recombinant metallothioneins: Wild type (BgwtMT) and the naturally mutated (BgKNMT) proteins. Red: cysteine residues; underlined blue: N-terminal additional residues introduced due to the recombinant expression conditions (see material and methods section); shaded in green: wildtype position of $\mathrm{K}$ (BgwtMT); shaded in yellow: its replacement by $\mathrm{N}$ in the natural allelic mutant (BgNKMT). The two protein sequences can be found in the GenBank under the following accession numbers: KT697617 (BgwtMT); and KY963493 (BgKNMT).

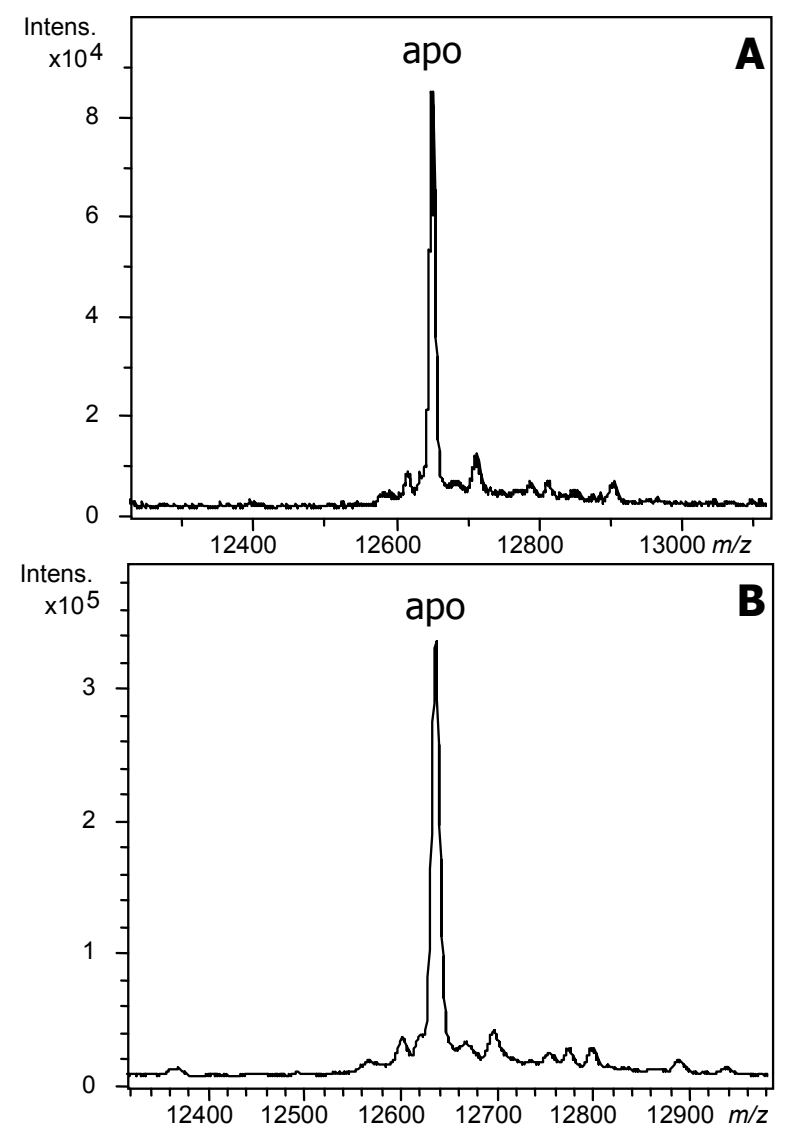

Figure 2. MS spectra of BgMT proteins: Deconvoluted electrospray ionization mass spectrometry (ESI-MS) spectra of the bacterial recombinant production of (A) BgwtMT (Experimental Molecular Mass: 12,652) and (B) BgKNMT (Experimental Mass: 12,639) in Zn-enriched media, recorded at pH 2.4.

\subsection{Divalent Zn(II) and Cd(II)-Binding Features of BgwtMT and BgKNMT}

The recombinant production of BgwtMT in Zn-enriched media rendered a mixture of several metallated species (Figure 3, Table 1) with $\mathrm{Zn}_{11}$ - and $\mathrm{Zn}_{10}$-BgwtMT being the most abundant ones (Figure 3A). Similarly, the production of the BgKNMT mutant form rendered the same mixture of metal-loaded species, even if the most intense peak correlates with $\mathrm{Zn}_{10}$-BgKNMT (Figure 3B). The CD spectra of both preparations (Figure 3C) are very similar (an exciton coupling band centered at approx. 
$240 \mathrm{~nm}$, corresponding to the expected $\mathrm{Zn}$-(SCys) 4 binding chromophores), thus suggesting a similar folding of both proteins about the $\mathrm{Zn}(\mathrm{II})$ ions.
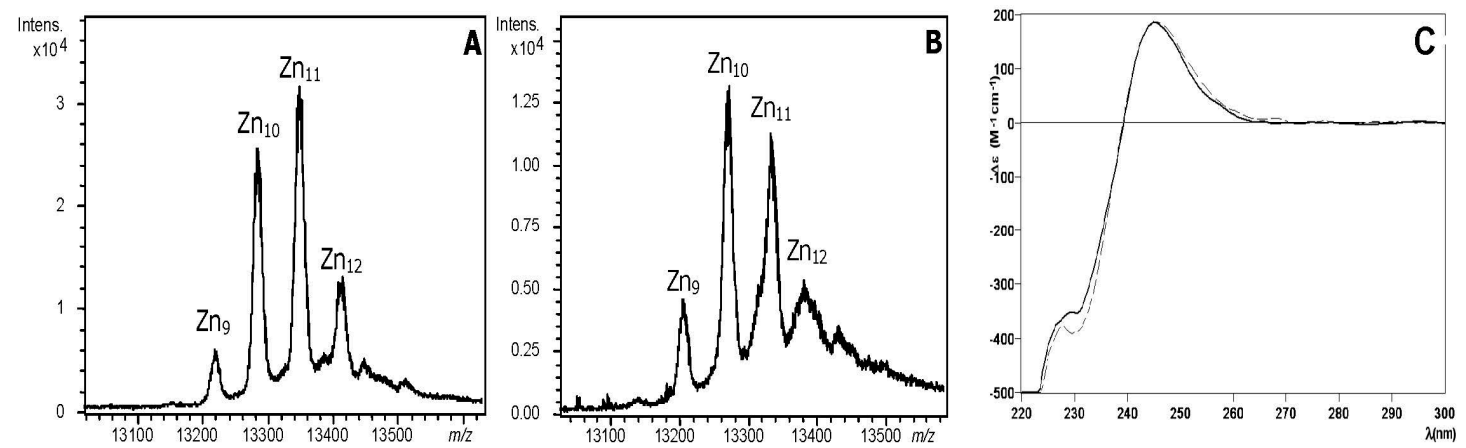

Figure 3. MS and circular dichroism (CD) spectra of Zn-BgMT: Deconvoluted ESI-MS spectra of the recombinant (A) Zn-BgwtMT and (B) Zn-BgKNMT, recorded at neutral (7.0) pH; (C) CD spectra of each Zn(II)-preparation: BgwtMT (solid line) and BgKNMT (dashed).

Table 1. Analytical characterization of the recombinant Zn-, Cd- and Cu-preparations of BgwtMT and BgKNMT. All data for the copper supplemented cultures correspond to normal aeration conditions, since no complexes could be recovered from low aerated cultures. Abbreviations: MT: Metallothionein, ICP-AES: Inductively coupled plasma atomic emission spectroscopy, ESI-MS: electrospray ionization mass spectrometry, Exp. MM: expected molecular mass, Calc. MM: calculated molecular mass.

\begin{tabular}{|c|c|c|c|c|c|c|c|c|}
\hline $\begin{array}{l}\text { Supplemented } \\
\text { Metal }\end{array}$ & MT & ICP-AES $^{a}$ & $\begin{array}{c}\text { ESI-MS }^{b} \\
\text { pH } 7.0\end{array}$ & $\begin{array}{c}\text { Exp. } \\
\text { MM }^{\text {c }}\end{array}$ & $\begin{array}{l}\text { Calc. } \\
\text { MM }^{\mathrm{d}}\end{array}$ & $\begin{array}{c}\text { ESI-MS }^{\text {b }} \\
\text { pH } 2.4\end{array}$ & $\begin{array}{c}\text { Exp. } \\
\text { MM }^{\text {c }}\end{array}$ & $\begin{array}{c}\text { Calc. } \\
\text { MM }^{\mathrm{d}}\end{array}$ \\
\hline \multirow{2}{*}{$\mathrm{Zn}$} & BgwtMT & $\begin{array}{l}9.8 \mathrm{Zn} \\
0 \mathrm{Cd} \\
0 \mathrm{Cu}\end{array}$ & $\begin{array}{l}\mathrm{Zn}_{9^{-}} \\
\mathrm{Zn}_{10^{-}} \\
\mathrm{Zn}_{11^{-}} \\
\mathrm{Zn}_{12^{-}}\end{array}$ & $\begin{array}{l}13,221 \\
13,286 \\
13,350 \\
13,414 \\
\end{array}$ & $\begin{array}{l}13,222.8 \\
13,286.2 \\
13,349.6 \\
13,413.0 \\
\end{array}$ & apo- & 12,652 & $12,652.3$ \\
\hline & BgKNMT & $\begin{array}{l}9.4 \mathrm{Zn} \\
0 \mathrm{Cd} \\
0 \mathrm{Cu}\end{array}$ & $\begin{array}{l}\mathrm{Zn}_{9^{-}} \\
\mathrm{Zn}_{1^{-}} \\
\mathrm{Zn}_{11^{-}} \\
\mathrm{Zn}_{12^{-}}\end{array}$ & $\begin{array}{l}13,207 \\
13,272 \\
13,336 \\
13,400 \\
\end{array}$ & $\begin{array}{l}13,208.7 \\
\mathbf{1 3}, \mathbf{2 7 2 . 1} \\
\mathbf{1 3}, 335.5 \\
13,398.9\end{array}$ & apo- & 12,639 & $12,638.2$ \\
\hline \multirow{2}{*}{$\mathrm{Cd}$} & BgwtMT & $\begin{array}{c}0 \mathrm{Zn} \\
12.9 \mathrm{Cd} \\
0 \mathrm{Cu}\end{array}$ & $\begin{array}{l}\mathrm{Cd}_{12^{-}} \\
\mathrm{Cd}_{13^{-}} \\
\mathrm{Cd}_{14} \mathrm{~S}^{-} \\
\mathrm{Cd}_{15^{-}} \mathrm{S}^{-} \\
\mathrm{Cd}_{16^{-}}\end{array}$ & $\begin{array}{l}13,980 \\
14,090 \\
\mathbf{1 4 , 2 2 9} \\
14,341 \\
14,418 \\
\end{array}$ & $\begin{array}{l}13,977.2 \\
14,087.6 \\
\mathbf{1 4 , 2 3 0 . 0} \\
14,340.5 \\
14,418.9 \\
\end{array}$ & $\begin{array}{l}\text { apo- } \\
\mathrm{Cd}_{7} \mathrm{~S}- \\
\mathrm{Cd}_{8} \mathrm{~S}-\end{array}$ & $\begin{array}{l}12,652 \\
13,457 \\
\mathbf{1 3}, \mathbf{5 6 7}\end{array}$ & $\begin{array}{l}12,652.3 \\
13,457.2 \\
13,567.6\end{array}$ \\
\hline & BgKNMT & $\begin{array}{c}0 \mathrm{Zn} \\
13.3 \mathrm{Cd} \\
0 \mathrm{Cu}\end{array}$ & $\begin{array}{l}\mathrm{Cd}_{12^{-}} \\
\mathrm{Cd}_{13^{-}} \\
\mathrm{Cd}_{14} \mathrm{~S}^{-} \\
\mathrm{Cd}_{15^{-}} \mathrm{S}^{-} \\
\mathrm{Cd}_{16^{-}}\end{array}$ & $\begin{array}{l}13,960 \\
14,075 \\
\mathbf{1 4 , 2 1 5} \\
14,327 \\
14,406 \\
\end{array}$ & $\begin{array}{l}13,963.2 \\
14,073.6 \\
\mathbf{1 4}, \mathbf{2 1 6 . 0} \\
14,326.4 \\
14,404.8 \\
\end{array}$ & $\begin{array}{l}\text { apo- } \\
\mathrm{Cd}_{7} \mathrm{~S}- \\
\mathrm{Cd}_{8} \mathrm{~S}-\end{array}$ & $\begin{array}{l}\mathbf{1 2 , 6 3 8} \\
13,442 \\
\mathbf{1 3}, \mathbf{5 5 3}\end{array}$ & $\begin{array}{l}\mathbf{1 2}, \mathbf{6 3 8 . 2} \\
13,443.1 \\
\mathbf{1 3}, \mathbf{5 5 3 . 5}\end{array}$ \\
\hline \multirow{2}{*}{$\mathrm{Cu}$} & BgwtMT & $\begin{array}{c}3.7 \mathrm{Zn} \\
0 \mathrm{Cd} \\
9.5 \mathrm{Cu}\end{array}$ & $\begin{array}{l}\mathrm{M}_{11}-\mathrm{MT} \\
\mathrm{M}_{12}-\mathrm{MT} \\
\mathbf{M}_{13}-\mathbf{M T} \\
\mathbf{M}_{14}-\mathbf{M T} \\
\mathrm{M}_{15}-\mathrm{MT} \\
\mathrm{M}_{16}-\mathrm{MT}\end{array}$ & $\begin{array}{l}13,341 \\
13,403 \\
\mathbf{1 3 , 4 6 7} \\
\mathbf{1 3 , 5 2 9} \\
13,588 \\
13,653\end{array}$ & $\begin{array}{l}13,340.4 \\
13,402.9 \\
\mathbf{1 3}, 465.5 \\
\mathbf{1 3}, \mathbf{5 2 8 . 0} \\
13,590.6 \\
13,653.1\end{array}$ & $\begin{array}{l}\mathrm{Cu}_{8}-\mathrm{MT} \\
\mathrm{Cu}_{9}-\mathrm{MT} \\
\mathrm{Cu}_{10}-\mathrm{MT} \\
\mathrm{Cu}_{11}-\mathrm{MT} \\
\mathrm{Cu}_{12}-\mathrm{MT} \\
\mathrm{Cu}_{13}-\mathrm{MT} \\
\mathrm{Cu}_{14}-\mathrm{MT}\end{array}$ & \begin{tabular}{l|}
13,153 \\
13,215 \\
13,277 \\
13,340 \\
13,403 \\
13,465 \\
13,526 \\
\end{tabular} & $\begin{array}{l}13,152.7 \\
13,215.3 \\
13,277.8 \\
13,340.4 \\
\mathbf{1 3}, \mathbf{4 0 2 . 9} \\
13,465.5 \\
13,528.0\end{array}$ \\
\hline & BgKNMT & $\begin{array}{c}1.9 \mathrm{Zn} \\
0 \mathrm{Cd} \\
9.9 \mathrm{Cu}\end{array}$ & $\begin{array}{l}\mathrm{M}_{13}-\mathrm{MT} \\
\mathrm{M}_{14}-\mathrm{MT} \\
\mathbf{M}_{15}-\mathrm{MT} \\
\mathbf{M}_{16}-\mathrm{MT} \\
\mathrm{M}_{17}-\mathrm{MT} \\
\mathrm{M}_{18}-\mathrm{MT}\end{array}$ & $\begin{array}{l}13,452 \\
13,514 \\
\mathbf{1 3}, 577 \\
\mathbf{1 3 , 6 3 9} \\
13,701 \\
13,762\end{array}$ & $\begin{array}{l}13,451.4 \\
13,513.9 \\
13,576.5 \\
13,639.0 \\
13,701.6 \\
13,764.1\end{array}$ & $\begin{array}{l}\mathrm{Cu}_{12}-\mathrm{MT} \\
\mathrm{Cu}_{13}-\mathrm{MT} \\
\mathrm{Cu}_{14}-\mathrm{MT} \\
\mathrm{Cu}_{15}-\mathrm{MT} \\
\mathrm{Cu}_{16}-\mathrm{MT} \\
\mathrm{Cu}_{17}-\mathrm{MT}\end{array}$ & $\begin{array}{l}13,388 \\
13,450 \\
\mathbf{1 3}, \mathbf{5 1 4} \\
13,575 \\
13,637 \\
13,697\end{array}$ & $\begin{array}{l}13,388.8 \\
13,451.4 \\
\mathbf{1 3}, \mathbf{5 1 3 . 9} \\
13,576.5 \\
13,639.0 \\
13,701.6\end{array}$ \\
\hline
\end{tabular}

a metal-to-peptide ratio calculated from $\mathrm{S}, \mathrm{Zn}, \mathrm{Cd}$ and $\mathrm{Cu}$ content (ICP-AES) data); ${ }^{\mathrm{b}}$ The stoichiometry of the metal-loaded complex was calculated from the mass difference between the holo- and the apo-peptides; Major species are highlighted in bold. $\mathrm{M}$ denotes mixtures of $\mathrm{Zn}$ and $\mathrm{Cu} ;{ }^{\mathrm{c}}$ Experimental molecular masses corresponding to the detected metal-complexes. The corresponding ESI-MS spectra are shown in Figures $2-4$ and Figure $6{ }^{\mathrm{d}}$ Theoretical molecular masses corresponding to the metal-complexes. 

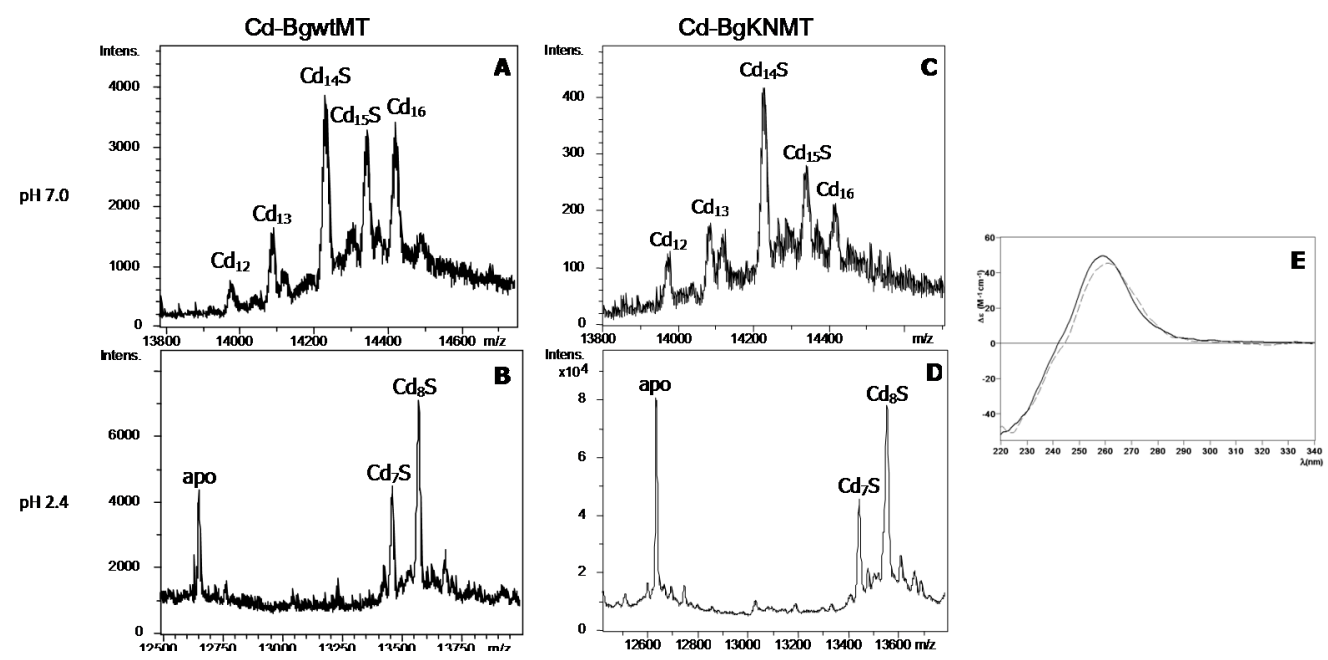

Figure 4. MS and CD spectra of Cd-BgMT: (A-D) Deconvoluted ESI-MS spectra of recombinant Cd-BgwtMT and Cd-BgKNMT, recorded at neutral (7.0) and acidic (2.4) pH; (E) CD spectra of each Cd(II) preparation: BgwtMT (solid line) and BgKNMT (dashed).

The ESI-MS analyses at neutral $\mathrm{pH}$ of the recombinant production of BgwtMT and BgKNMT in Cd-supplemented E. coli cultures (Figure 4, Table 1) revealed the formation of the same species in both preparations (with similar relative abundances), with the important presence of one major sulfide-containing species $\left(\mathrm{Cd}_{14} \mathrm{~S}-\mathrm{BgMT}\right)$ accompanied by minor amounts of $\mathrm{Cd}_{15}-\mathrm{S}, \mathrm{Cd}_{16^{-}}, \mathrm{Cd}_{13^{-}}$and $\mathrm{Cd}_{12}$-MT. Interestingly, the mass spectra of both samples recorded at $\mathrm{pH} 2.4$ revealed the remaining presence of $\mathrm{Cd}_{7} \mathrm{~S}$ - and $\mathrm{Cd}_{8} \mathrm{~S}$-BgMT complexes coexisting with the apo-form. In every case, the decrease of $\mathrm{pH}$ down to 0.9 was necessary to completely remove all $\mathrm{Cd}$ (II) initially bound to proteins (data not shown). The CD spectra of the Cd-BgwtMT and Cd-BgKNMT preparations (Figure 4) display the contribution of both (1) a Gaussian band centered at ca. $250 \mathrm{~nm}$, corresponding to the Cd-(SCys) chromophores and (2) a contribution of a further absorption at ca. $280 \mathrm{~nm}$ in agreement with the presence of $\mathrm{Cd}_{-} \mathrm{S}^{2-}$ chromophores in these samples. Furthermore, the congruence of the respective CD fingerprints confirmed equivalent folds of BgwtMT and BgKNMT when coordinating Cd(II) ions.

In order to further study the capabilities of the BgwtMT and BgKNMT proteins for $\mathrm{Cd}(\mathrm{II})$ binding, the recombinant $\mathrm{Zn}$-BgwtMT and $\mathrm{Zn}$-BgKNMT preparations were titrated with $\mathrm{Cd}(\mathrm{II})$ and the $\mathrm{Zn} / \mathrm{Cd}$ metal displacement reactions were followed in parallel by ESI-MS and CD spectroscopy (Figure 5). CD signals from both titrations proceeded very similarly: the addition of $\mathrm{Cd}(\mathrm{II})$ provoked a red shift of the maxima until $12 \mathrm{Cd}$ (II) equivalents were added; further additions led to a decrease of the intensity suggesting unfolding of the formed clusters. These data are in agreement with the measured mass data. They show the subsequent replacement of the initial Zn(II) through formation of heteronuclear $\mathrm{Zn}$, $\mathrm{Cd}$-species, until the system is saturated after the addition $12 \mathrm{Cd}(\mathrm{II})$ equivalents. Even when adding more $\mathrm{Cd}(\mathrm{II})$ the main species were still $\mathrm{Cd}_{12}$ and $\mathrm{Cd}_{13}$-BgMT. Other species $\left(\mathrm{Cd}_{11}-\right.$ and $\mathrm{Cd}_{14}-\mathrm{BgMT}$ as well as $\mathrm{Cd}_{11} \mathrm{Zn}_{1}$ - and $\mathrm{Cd}_{12} \mathrm{Zn}_{1}$-BgMT) were also present to minor amounts. 


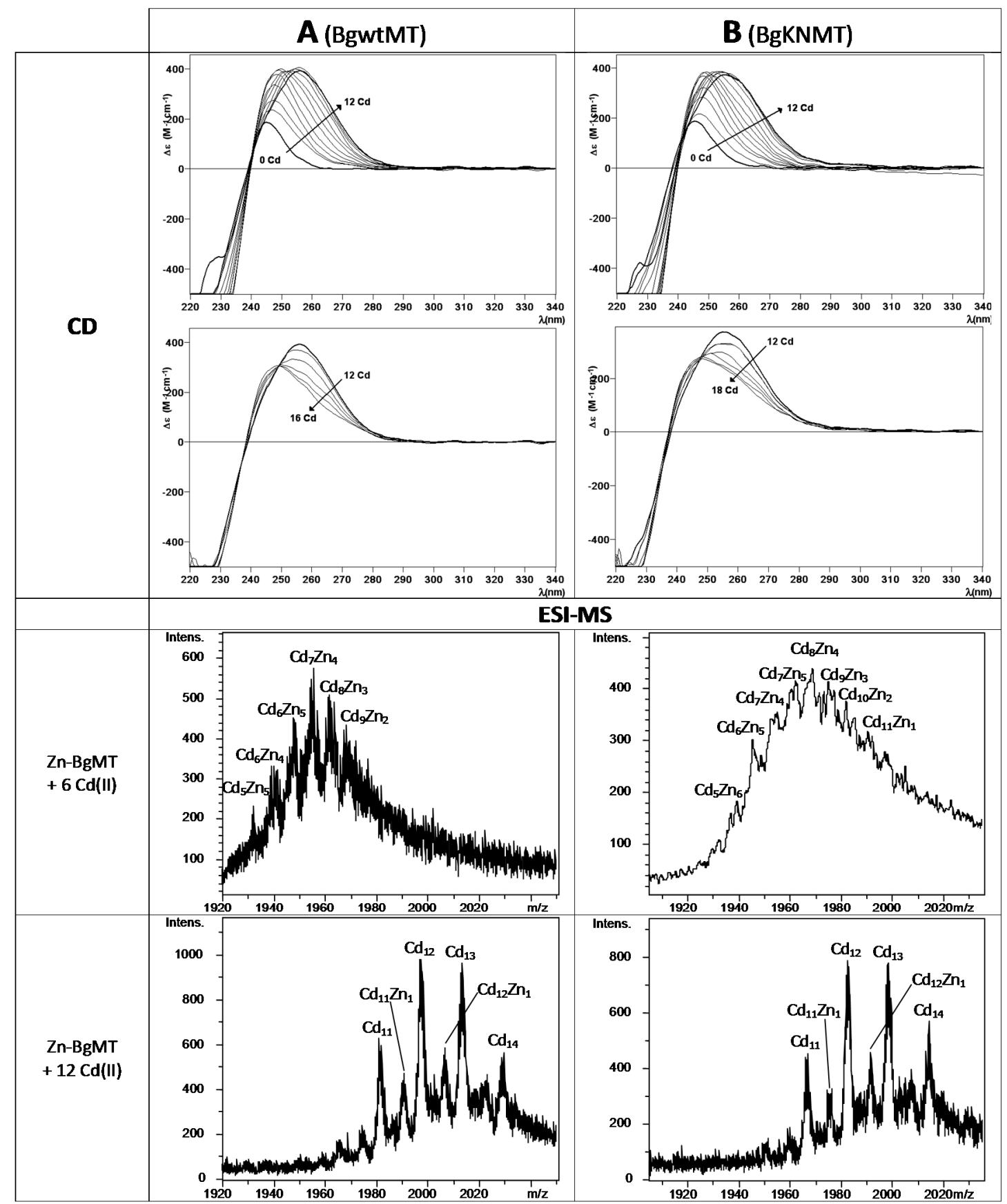

Figure 5. $\mathrm{CD}$ and ESI-MS spectra of $\mathrm{Zn} / \mathrm{Cd}$ replacement of BgMT: Shown are spectra (at the +7 charge state) corresponding to the $\mathrm{Zn}$ (II)/Cd(II) replacement reaction of recombinant (A) Zn-BgwtMT and (B) Zn-BgKNMT, recorded at neutral $\mathrm{pH}$. In both cases, a $5 \mu \mathrm{M}$ solution of Zn-BgMT was titrated with up to $16-18$ equivalents of $\mathrm{CdCl}_{2}$ at neutral $\mathrm{pH}$.

\subsection{Monovalent-Cu(I)-Binding Features of BgwtMT and BgKNMT}

The main differences between BgwtMT and BgKNMT were observed when producing them recombinantly in $\mathrm{Cu}$-enriched media under standard or low aeration conditions (Figure 6). Although the two conventional types of Cu-supplemented productions [15] at standard (low intracellular copper content) or at low aeration (high intracellular copper content) conditions were assayed, several efforts to purify BgwtMT and BgKNMT from E. coli cultures grown at low oxygen conditions failed. Contrarily, both proteins could be isolated under normal aeration conditions, and were analyzed 
by ESI-MS and CD for comparison. Interestingly, both preparations exhibited a similar pattern: No stable species were observed, neither under the low aeration conditions nor under normal aeration conditions-both yielded a mixture of heterometallic Zn, Cu-species (Figure 6, Table 1).
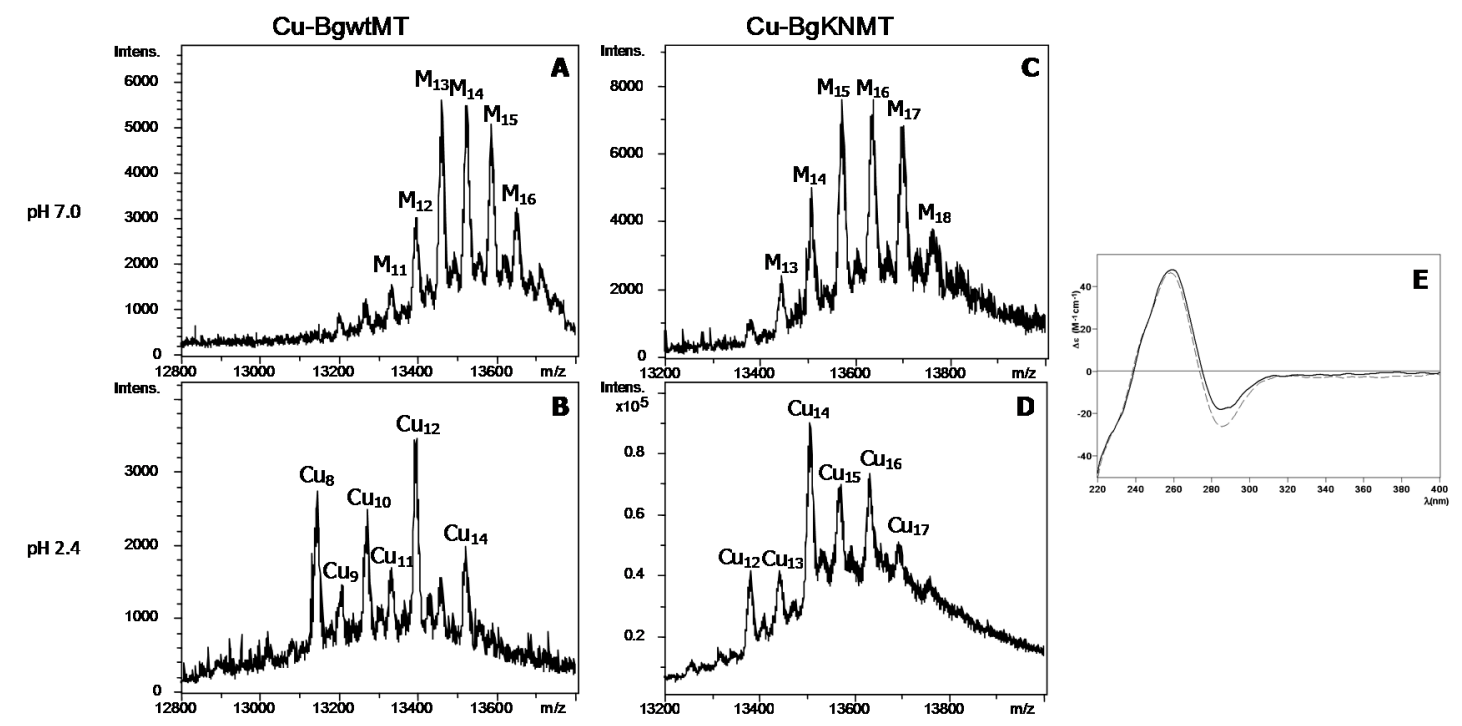

Figure 6. MS and CD spectra of Cu-BgMT: (A-D) Deconvoluted ESI-MS spectra of recombinant $\mathrm{Cu}$-BgwtMT and Cu-BgKNMT, recorded at neutral (7.0) and acidic (2.4) pH. M denotes mixture of Zn and $\mathrm{Cu}(\mathrm{E}) \mathrm{CD}$ spectra of each Cu-preparation: BgwtMT (solid line) and BgKNMT (dashed).

However, while for BgwtMT the main species at neutral pH contains 13 metal ions $\left(\mathrm{M}_{13}\right.$-BgwtMT, with $\mathrm{M}=\mathrm{Zn}+\mathrm{Cu}$ ), and $\mathrm{Cu}_{8}$ - and $\mathrm{Cu}_{12}$-BgwtMT at acidic $\mathrm{pH}$, the natural $\mathrm{BgKNMT}$ mutant protein can bind more metal. This was observed at both $\mathrm{pH}$ values, with $\mathrm{M}_{15^{-}}{ }^{-16}$ and $\mathrm{Cu}_{14}$-BgKNMT being the main peaks at neutral and acidic $\mathrm{pH}$, respectively (Figure 6C,D). The CD spectra were again very similar for both preparations (Figure 6E) and showed the typical absorbances at ca. 260 and $280 \mathrm{~nm}$ corresponding to $\mathrm{Cu}$-loaded MTs. Even if considering that the metal-speciation was slightly different in both preparations, the coexistence of several heterometallic (Zn,Cu-BgwtMT and Zn,Cu-BgKNMT) species probably resulted in a similar folding of both proteins about the metal ions, always dominated by the characteristic signals of the more abundant $\mathrm{Cu}(\mathrm{I})$. Zn just revealed its presence as a faint shoulder at ca. $240 \mathrm{~nm}$.

\subsection{Lacking Metal-Binding Specificity is an Eminent Feature of Wild-Type and Allelic Biomphalaria Glabrata MTs}

The fact that no single metallated species (with $\mathrm{Zn}^{2+}, \mathrm{Cd}^{2+}$ or even $\mathrm{Cu}^{+}$) could be obtained, neither in the recombinant productions, nor in the in vitro $\mathrm{Zn} / \mathrm{Cd}$ replacement, indicates the lack of a metal specificity for both studied proteins. The absence of metal-binding specificity is thus considered as an inherent feature of BgwtMT and BgKNMT. Interestingly, the natural mutation K/N of the wild-type protein did not significantly affect its binding of divalent metal ions, and both proteins (BgwtMT and BgKNMT) behaved very similarly when binding $\mathrm{Zn}(\mathrm{II})$ and $\mathrm{Cd}(\mathrm{II})$ (similar speciation and very similar folding) (Figure 4). Contrarily, there were remarkable differences between the wild-type and the mutant variant with respect to binding of $\mathrm{Cu}(\mathrm{I})$. In fact, the replacement of one single amino acid ( $\mathrm{K}$ by $\mathrm{N}$ ) altered the binding properties of the protein by significantly increasing its $\mathrm{Cu}$-binding capability, leading to species with a higher $\mathrm{Cu}(\mathrm{I})$ content than in the wild-type protein (Figure 6). This suggests that the replacement of $\mathrm{K}$ by $\mathrm{N}$ may have increased the $\mathrm{Cu}$-thionein character of the unspecific BgwtMT protein, in agreement with previously reported data concerning the CaCdCuMT isoform of the Cantareus aspersus MTs [16]. Overall, however, this did not significantly change the unspecific binding character of both BgMT proteins. 
The present findings are in contrast to the high metal-binding specificity of MTs from other gastropods, e.g., in case of the well characterized CdMT and CuMT isoforms of terrestrial snails from the Helicid family, including the Roman snail (Helix pomatia) [1,3] and the garden snail (Cantareus aspersus) [17], all belonging to the gastropod phylum of Stylommatophora. It is also true for the Cd-specific MT of the marine periwinkle (Littorina littorea), that belongs to the gastropod phylum of Caenogastropoda [4]. Altogether, our data indicate that metal-binding properties of gastropod MTs may vary in a lineage-specific manner.

2.5. Missing Metal Specificity of Recombinant BgMT Proteins Goes Hand in Hand with Lacking Upregulation of the BgMT Gene

While many genes of metal-specific MTs from other gastropod species can specifically be upregulated by exposure to their cognate metal ions [2,6], this was clearly not the case for the $M T$ gene of Biomphalaria glabrata (BgwtMT), at least upon exposure to $\mathrm{Cd}^{2+}$. While the metal itself was strongly accumulated in the midgut gland of $\mathrm{Cd}$-exposed individuals with a concentration factor about 500 times above control levels (Figure 7A), there was no concomitant upregulation of the MT mRNA concentration at all (Figure 7B). Instead, it appeared that mRNA levels of the BgMT in both untreated (control) and Cd-treated animals were already highly elevated, compared to transcription levels of other gastropod MT genes under control conditions. mRNA concentrations of the metal-specific CdMT genes of the terrestrial snails Helix pomatia and Cantareus aspersus under control conditions, for example [2,6], are about 8-15 times lower than the mRNA levels of the BgMT gene in untreated animals (Figure 7B). This strongly suggests that the $B g M T$ gene and protein may function in a different manner than the metal-specific MT genes and proteins of Helix pomatia and Cantareus aspersus species. Considering the concomitance of the lack of metal specificity and the missing Cd-dependent inducibility of the $B g M T$ gene, which is already highly expressed in controls, one obvious hypothesis is that the metal sequestration potential of BgMT may primarily be based on its metal replacement capacity rather than on a strong binding selectivity after metal-dependent induction and de novo synthesis. In fact, metal replacement reactions of the recombinant BgwtMT and BgKNMT proteins indicate that, at least in vitro, such replacement reactions (e.g., $\mathrm{Cd}^{2+}$ versus $\mathrm{Zn}^{2+}$ ) may take place without significantly impairing the protein integrity and structure (Figure 5).
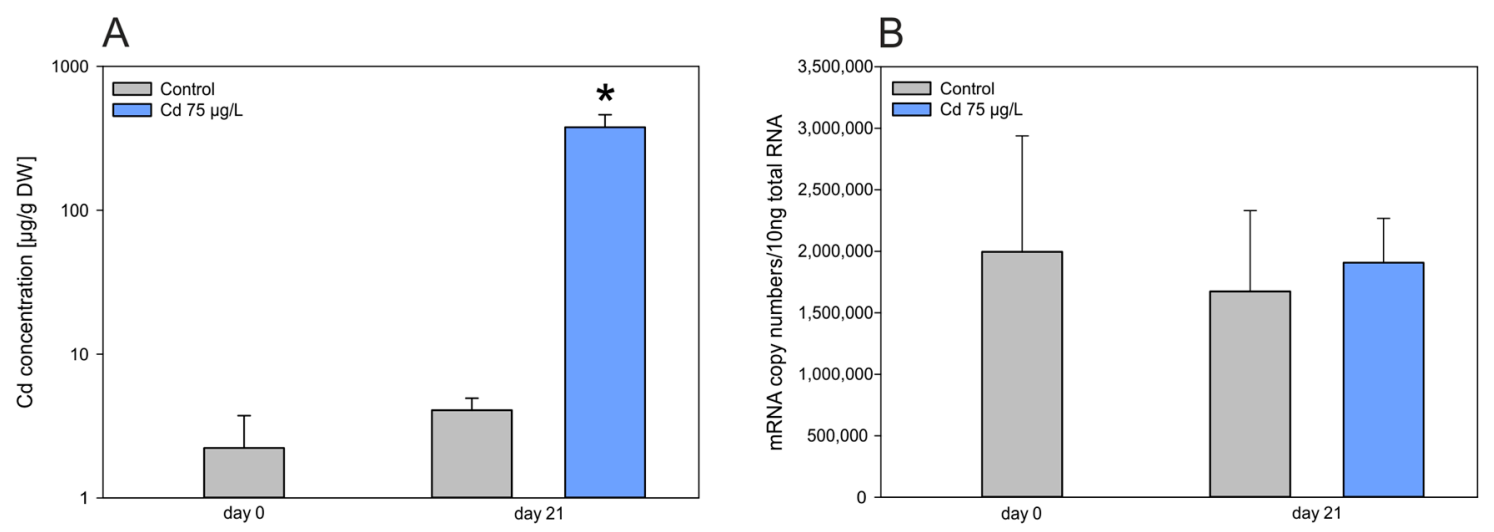

Figure 7. (A) Cd concentration in midgut gland tissue and qRT-PCR of mRNA after Cd exposure. (A) $\mathrm{Cd}$ concentration in midgut gland tissue of Biomphalaria glabrata on days 0 and day 21 of $\mathrm{Cd}$ exposure $(75 \mu \mathrm{g} / \mathrm{L}) ;\left({ }^{*} p<0.001\right)$; the $\mathrm{y}$-axis shows values in decadic logarithm; (B) Quantitative Real-Time PCR data of BgwtMT gene transcription on days 0 and 21 of Cd exposure $(75 \mu \mathrm{g} / \mathrm{L})$. Grey bars: control values; Blue bars: Cd exposure values. 
2.6. The Biomphalaria glabrata MT in the Context of Other Hygrophila MTs: Deviant Primary Structures and Metal Stoichiometries

As indicated above, the unspecific metal-binding properties of recombinant BgMT and the lacking upregulation capacity of the corresponding gene grossly deviate from features of the rather metal-specific MT proteins and their responsive cognate genes of many other gastropod species. Indeed, Biomphalaria glabrata seems to share some of its deviating MT features with snail species belonging, just as Biomphalaria glabrata does, to the monophyletic gastropod clade of Hygrophila that comprises, according to the current phylogeny, all air-breathing ("pulmonate") freshwater snails of the super-phylum of Panpulmonata [18]. While all so-far studied Hygrophila species seem to possess MTs [7,19], their cognate MT genes may only weakly or even hardly at all respond to heavy metal stress upon exposure. This was shown for Cd-exposed Physa acuta [9], metal-stressed Lymnaea stagnalis [20] or Cd-stressed Biomphalaria glabrata (this study). Instead, phytochelatin (PC) synthesis was recently demonstrated as a responsive reaction of Lymnaea stagnalis to Cd stress [8]. This suggests that apart from MTs, PC metal complexes may be formed in these aquatic snails in response to metal stress. It is not clear, however, if and how the PC system in these animals may interfere with the MT pool.

Interestingly, a primary sequence alignment of the Cd-specific MT isoform of Helix pomatia, HpCdMT, with several MT sequences of Hygrophila species (Figure 8) shows that, in contrast to the former, the MT sequences of Hygrophila species (including Physa acuta, Lymnaea stagnalis and Biomphalaria glabrata), do not show a clear two-domain organization with a straight forward Cys:divalent metal-binding ratio of 9:3 per domain. Instead, the Hygrophila MT sequences seem to suffer from structural "degeneration" by deletion, truncation or extension of their primary sequences, often with deviations from the above-mentioned model of the 9:3 Cys:divalent metal ratio [21] (Figure 8). It is not known if and how all these structural deviations may influence the metal-binding behavior of the respective single proteins, but it may be assumed that overall, these structural "degenerations" from the classical gastropod MT model may contribute to impairment of their metal-specific binding properties.

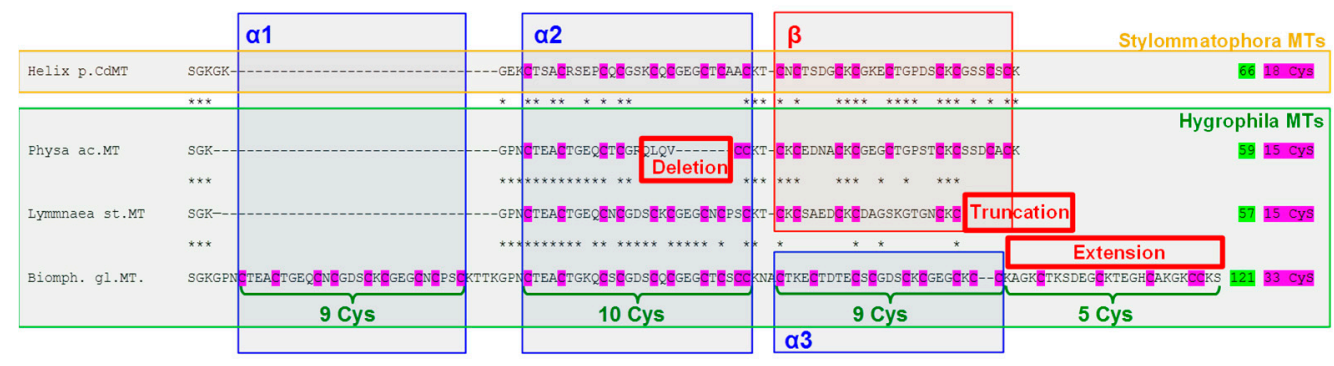

Figure 8. Sequence Alignment of sequences of various snail MTs: Alignment of Helix pomatia CdMT (Helix p.CdMT) (Stylommatophora MTs, orange-framed box) sequence with those of MTs of Hygrophila (Hygrophila MTs, green-framed box), including MTs of Physa acuta (Physa ac.MT), Lymnaea stagnalis MT (Lymnaea st.MT) and Biomphalaria glabrata MT (Biomph. gl.MT), showing the presumed domain organization with up to three $\alpha$ domains $(\alpha 1, \alpha 2$ and $\alpha 3$, blue-framed boxes) and one $\beta$ domain (red-framed box). Conserved cysteine positions in the MT sequences are underlaid in pink. Also indicated in green letters are the numbers of Cys residues in every single domain of the Biomphalaria gl. MT, along with primary structure deviations (Deletion, Truncation, Extension) in Hygrophila MTs from the Helix pomatia CdMT model. Identical amino acid residues between the aligned sequences are indicated by stars. The respective amino acid chain lengths of the MT peptides are highlighted in green near their C-terminal ends. Also indicated next to the C-termini are the numbers of Cys residues in each MT sequence (underlaid in pink). GenBank Accession numbers of the shown sequences are as follows: Helix pomatia CdMT, ACN66299.1; Physa acuta MT, GU259686; Lymnaea stagnalis MT, KT253648; Biomphalaria glabrata MT KT697617. 


\section{Materials and Methods}

\subsection{Primary Structure of BglMT}

The primary structure of the BglwtMT was elucidated by genome analysis within the Biomphalaria glabrata genome project (VectorBase, National Institutes of Health, Bethesda, MD, USA). The BglKNMT was obtained by screening for allelic variations and both sequences were experimentally verified by sequencing PCR-amplified and cloned individuals [13]. The sequences were submitted to the GenBank, and are available under the accession numbers KT697617 (BgwtMT) and KY963493 (BgKNMT).

\subsection{Cloning and Heterologous Expression of Biomphalaria glabrata BgwtMT and BgKNMT}

Synthetic cDNAs for the two allelic variants of the predicted Biomphalaria glabarata MTs were provided by Integrated DNA Technologies Company (Coralville, IA, USA). BamHI and XhoI restriction sites and 6-7 additional 5'-nucleotides were added to the BgMT cDNA ends to facilitate the cloning processes. The synthetic cDNAs were PCR amplified with specific primers 5'-TTTTATTGGATCCATGAGTGGCAAAG-3' (forward) and 5'-ATTTTTCTCGAGTCAACTCTTAC-3' (reverse), using Expand High Fidelity PCR system ${ }^{\circledR}$ (Roche, Penzberg, Upper Bavaria, Germany). A 25-cycle amplification reaction was performed under the following conditions: $30 \mathrm{~s}$ at $94{ }^{\circ} \mathrm{C}, 30 \mathrm{~s}$ at 55 ${ }^{\circ} \mathrm{C}$, and $45 \mathrm{~s}$ at $72{ }^{\circ} \mathrm{C}$, in a $25 \mu \mathrm{L}$ PCR mixture containing $25 \mathrm{ng}$ of template DNA, $0.01 \mathrm{mM}$ of each primer, and $0.0125 \mathrm{mM}$ of each dNTP. The amplified products were analyzed on a $1 \%$ agarose gel stained with Gel red (Biotum Inc., Bay Area, CA, USA). The BgMT cDNAs were digested with BamHI and XhoI enzymes, cloned into a BamHI-XhoI digested pGEX-4T-1 vector (GE Healthcare, Chicago, IL, USA) with the DNA Ligation Kit 2.1 ${ }^{\circledR}$ (Takara Bio Inc., Shimogyo-ku, Kyoto, Japan), and transformed into E. coli Dh5 $\alpha$ strain. Plasmid DNA was purified from bacteria using the GeneElute ${ }^{\mathrm{TM}}$ Plasmid Miniprep Kit (Sigma-Aldrich, St. Louis, MO, USA), screened for insert presence by digestion with ScaI enzyme, and sequenced using the BigDye ${ }^{\circledR}$ Terminator v3.1 Cycle Sequencing Kit (Applied Biosystems, Waltham, MA, USA) in an ABIPRISM 310 automatic sequencer (Applied Biosystems). DNA from each recombinant $B g M T$-pGEX plasmid was used to transform E. coli BL21 strain, a protease deficient strain used for heterologous protein expression.

The recombinant expression of BgMTs was assayed by growing $3 \mathrm{~mL}$ of LB- $25 \mathrm{mg} / \mathrm{mL}$ ampicillin medium inoculated with BgMT-producing E. coli BL21 strains. After growth overnight at $37{ }^{\circ} \mathrm{C}$ and $250 \mathrm{rpm}, 0.3 \mathrm{~mL}$ of the culture was used to inoculate $3 \mathrm{~mL}$ of fresh medium and new cultures were grown for $2 \mathrm{~h}$. The expression of the $B g M T$ s was induced with $100 \mu \mathrm{M}$ (final concentration) of isopropyl- $\beta$-D-thiogalactopyranoside (IPTG) for $3 \mathrm{~h}$. After $30 \mathrm{~min}$ of induction, cultures were supplemented with $500 \mu \mathrm{M}$ of $\mathrm{CuSO}_{4}, 300 \mu \mathrm{M}$ of $\mathrm{CdCl}_{2}$ or $300 \mu \mathrm{M}$ of $\mathrm{ZnCl}_{2}$ (final concentrations), and allowed to grow for further $2.5 \mathrm{~h}$ for the synthesis of the respective metal complexes. Cells were harvested by centrifugation for $1 \mathrm{~min}$ at 13,000 rpm, and bacterial pellets were suspended by vortexing in $150 \mu \mathrm{L}$ of Phosphate Buffered Saline (PBS1X) (140 mM NaCl, $2.7 \mathrm{mM} \mathrm{KCl,} 10.1 \mathrm{mM}$ $\mathrm{Na}_{2} \mathrm{HPO}_{4}, 1.8 \mathrm{mM} \mathrm{Kh} \mathrm{PO}_{4}$ ). Suspended cells were sonicated (Sonifier ${ }^{\circledR}$ ultrasonic cell disruptor, Ferguson, MO, USA) at voltage 2 with 9 pulses of $0.6 \mathrm{~s}$, and then centrifuged for 10 min at 12,500 rpm at $4{ }^{\circ} \mathrm{C}$. Supernatant was recovered, and protein content was measured by a Bradford assay (Bio-Rad, Hercules, CA, USA ) in a Nanoquant infinite M200 microplate reader (Infinite M200 TECAN). Expression of both $B g M T s$ was analyzed by sodium dodecyl sulfate polyacrylamide gel electrophoresis (SDS-PAGE) on $12.5 \%$ gels stained with Coomassie Blue.

\subsection{Synthesis and Purification of Recombinant BgwtMT and BgKNMT}

The BgMT metal complexes were biosynthesized in $5 \mathrm{~L}$ Erlenmeyer cultures of the corresponding transformed E. coli $\mathrm{Bl} 21$ cells grown in LB medium containing $100 \mathrm{mg} / \mathrm{mL}$ ampicillin supplemented with $\mathrm{ZnCl}_{2}(300 \mu \mathrm{M}), \mathrm{CdCl}_{2}(300 \mu \mathrm{M})$ or $\mathrm{CuSO}_{4}(500 \mu \mathrm{M})$. For copper cultures, two different aeration conditions were applied (250 rpm-standard aeration and $150 \mathrm{rpm}$-low aeration), of which only the standard aeration culture was successful. BgMT synthesis was induced with 
isopropyl-1-thio- $\beta$-D-galactopyranoside (IPTG) at a final concentration of $100 \mu \mathrm{M}$ for $30 \mathrm{~min}$. After adding the metal solution followed by a $2.5 \mathrm{~h}$ induction, cells were harvested by centrifugation. The protein containing pellets were re-suspended in $4{ }^{\circ} \mathrm{C}$ PBS $1 \times$ supplied with $0.5 \%(v / v)$ B-mercaptoethanol, sonicated and centrifuged at $12,000 \times g$ for $40 \mathrm{~min}$ at $4{ }^{\circ} \mathrm{C}$. Glutathione S-transferase (GST)-BgMT polypeptides were purified using batch affinity chromatography with glutathione sepharose (GE Healthcare, Buckinghamshire, UK). After incubation for one hour at room temperature applying constant agitation, the mix was washed in PBS three times. Argon was bubbled through all the washing steps following cell disruption to avert oxidation of the metal-BgMT complexes. Thrombin (GE Healthcare, Buckinghamshire, UK) $(1 \mu \mathrm{L} / \mathrm{mg}$ of fusion protein) was added to the mixture and digestion was carried out overnight at $16^{\circ} \mathrm{C}$. This enabled separation of the GST fragment, which remained bound to the gel matrix, from the fusion protein. The eluted solution was applied to Centriprep low Concentrators (Amicon, Millipore, MA, USA) with a cut-off of $3 \mathrm{kDa}$ and subsequently fractionated by means of fast protein liquid chromatography (FPLC), using a Superdex-75 column (GE Healthcare) equilibrated with $50 \mathrm{mM}$ Tris- $\mathrm{HCl}, \mathrm{pH}$ 7.0, and run at $1 \mathrm{~mL} / \mathrm{min}$. Fractions were collected and the protein content was analyzed by its absorbance at $254 \mathrm{~nm}$. Samples containing BgMT were pooled and stored at $-80^{\circ} \mathrm{C}$.

\subsection{Zn(II)/Cd(II) Replacement Reactions in the Zn(II)-BgMT Proteins}

Reactions of $\mathrm{Zn}$ (II) displacement by Cd(II) on the recombinant Zn-BgMT preparations were performed as described elsewhere [22]. This allowed the formation of the Cd-"in vitro complexes" by addition of several molar equivalents of $\mathrm{Cd}^{2+}$ from a standard solution to the corresponding Zn-BgMT preparation. These experiments were performed at constant $\mathrm{pH} 7.0$ without the addition of any extra buffers, and under argon atmosphere.

\subsection{Spectroscopic Analyses (ICP-AES, UV-Vis and CD) of the Metal Complexes Formed by the BgwtMT and BgKNMT Proteins}

Determination of the sulfur and metal content of all the metal-BgMT samples was performed by Inductively Coupled Plasma Atomic Emission Spectroscopy (ICP-AES) in a Polyscan 61E (Thermo Jarrel Ash, Franklin, MA, USA) spectrometer by measuring $\mathrm{S}$ at $182.040 \mathrm{~nm}, \mathrm{Zn}$ at 213.856 $\mathrm{nm}, \mathrm{Cd}$ at 228.802, and $\mathrm{Cu}$ at $324.803 \mathrm{~nm}$. This allowed determination of the protein concentration by considering that all $\mathrm{S}$ atoms were provided by the BgMT peptides. A Jasco spectropolarimeter (Model J-715, JASCO, Groß-Umstadt, Germany) interfaced to a computer (J700 software, JASCO, Groß-Umstadt, Germany) was used for circular dichroism (CD) measurements. The electronic absorption measurements were performed in an HP-8453 Diode array UV-vis spectrophotometer (GIM, Ramsey, MN, USA) in 1-cm capped quartz cuvettes. In all spectroscopic measurements the dilution effects were corrected and processed using the GRAMS 32 software (Thermo Fisher Scientific, Waltham, MA, USA).

\subsection{Electrospray Ionization Time-of-Flight Mass Spectrometry (ESI-TOF MS) of the Metal Complexes Obtained from the BgMT proteins}

The $M_{\mathrm{W}}$ determinations by electrospray ionization time-of-flight mass spectrometry (ESI-TOF MS) were carried out in a Micro TOF-Q instrument (Bruker Daltonics, Bremen, Germany) interfaced with a Series 1200 HPLC Agilent pump and equipped with an autosampler, all of which were controlled by the Compass Software. ESI-L Low Concentration Tuning Mix (Agilent Technologies, Santa Clara, CA, USA) was used for calibration. The samples were analyzed using a 5:95 mixture of acetonitrile:ammonium acetate $(15 \mathrm{mM}, \mathrm{pH} 7.0)$ or a 5:95 acetonitrile:formic acid mixture (at $\mathrm{pH} 2.4)$ as carrier buffers. The neutral $\mathrm{pH}$ buffer allowed to detect all the metallated species while the acidic conditions provoke the release of $\mathrm{Zn}(\mathrm{II})$ and $\mathrm{Cd}(\mathrm{II})$, but keep the $\mathrm{Cu}(\mathrm{I})$ ions bound to the proteins.

Experimental mass values were calculated as described in [23] and the error associated with the measurements resulted to be always smaller than $0.1 \%$. 


\subsection{Experimental Set-Up for BgMT Gene Induction Studies}

Individuals of Biomphalaria glabrata originated from a laboratory-grown culture at the Institute of Zoology in Innsbruck, where the snails were kept in freshwater aquarium tanks at $25^{\circ} \mathrm{C}$ with a $12: 12 \mathrm{~h}$ photoperiod. Snails were fed ad libitum with commercially available lettuce (Lactuca sativa) every third day.

Prior to the experiment, forty individuals of Biomphalaria glabrata were acclimatized for two weeks in reconstituted water $\left(\mathrm{KCl} 18 \mathrm{mg} / \mathrm{L}, \mathrm{MgSO}_{4} 190 \mathrm{mg} / \mathrm{L}, \mathrm{NaHCO}_{3} 98.5 \mathrm{mg} / \mathrm{L}, \mathrm{CaCl}_{2} 450 \mathrm{mg} / \mathrm{L}\right.$ and $\mathrm{NaCl} 430 \mathrm{mg} / \mathrm{L}$ in milliQ water). Afterwards, snails were separated into different tanks and a Cd exposure regime was applied by adding $\mathrm{CdCl}_{2}$ to a final $\mathrm{Cd}$ concentration of $75 \mu \mathrm{g} / \mathrm{L}$. A control group of 20 individuals was kept in Cd-free reconstituted water as a reference. Resulting $\mathrm{Cd}$ concentrations in the water were as follows (mean \pm standard deviation, $n=5$ ): Control, $0.24 \pm 0.14 \mu \mathrm{g} / \mathrm{L} ; \mathrm{Cd}$ exposure, $63 \pm 7.6 \mu \mathrm{g} / \mathrm{L}$. Throughout the experiment the snails were fed with lettuce ad libitum. Four snails of each group were sampled on day 0 and 21. All sampled individuals were dissected and the midgut gland tissue was used for RNA isolation and tissue $\mathrm{Cd}$ analysis as described below.

\section{8. $m R N A$ Isolation, Reverse Transcription and BgMT qRT-PCR}

Biomphalaria glabrata individuals were dissected on an ice-cooled stainless steel plate and $\sim 10$ $\mathrm{mg}$ (fresh weight) of midgut gland tissue was used for RNA isolation. The remaining midgut gland tissue of each animal was processed further for $\mathrm{Cd}$ analysis as described below. Tissue samples were homogenized (Precellys, Bertin instruments, France) and total RNA was isolated with the RNeasy ${ }^{\circledR}$ Plant Mini Kit (Qiagen) applying on-column DNase 1 digestion (Qiagen). Quantification was achieved by means of the RiboGreen ${ }^{\circledR}$ RNA Quantification Kit from Molecular Probes (Invitrogen, Karlsruhe, Germany) on a VICTOR ${ }^{\mathrm{TM}}$ X4 2030 Multilabel Reader (PerkinElmer, Waltham, MA, USA). 250 ng RNA were subjected to cDNA synthesis (Superscript ${ }^{\circledR}$ IV Reverse Transcriptase, Invitrogen, Life Technologies, Waltham, MA, USA) in a $20 \mu \mathrm{L}$ approach for subsequent Real-time Detection PCR.

Quantitative Real-time Detection PCR of BgwtMT cDNA was performed on a Quant studio 3 (Applied Biosystems, Thermo Fisher Scientific) using Power SYBR Green (Applied Biosystems). RT Primers were designed using the Primer Express 3.0 software (Applied Biosystems) and optimal primer concentrations were assessed with a primer-matrix followed by dissociation curves. The BgMT transcript with the defined amplicon length $(107 \mathrm{bp})$ was amplified with the following primers and concentrations: BgMT sense, $900 \mathrm{nM}$; 5'-GCACTGACACAGAATGCAGTTG-3' and BgMT antisense, $900 \mathrm{nM} ; 5^{\prime}$-TTTGCACCCTTCATCTGACTTAGT-3' applying the following protocol of 40 cycles: denaturation at $95{ }^{\circ} \mathrm{C}$ for $15 \mathrm{~s}$, annealing and extension combined at $60{ }^{\circ} \mathrm{C}$ for $60 \mathrm{~s}$. Subsequently calibration curves from amplicons were generated to determine $C_{\mathrm{q}}$ values for copy number analysis (PCR efficiency $\sim 96 \%$ ) using the Thermo Fisher Cloud Software, Version 1.0 (Life Technologies Corporation, Waltham, MA, USA). The $10-\mu \mathrm{L}$ PCR reaction contained $1 \mu \mathrm{L}$ of cDNA and $1 \times$ Power SYBR Green PCR master mix, $1 \times$ U-BSA and sense and antisense primer.

\subsection{Metal Analysis}

$\mathrm{Cd}$ concentrations in the midgut gland tissues and the medium were assessed by flame atomic absorption spectrophotometry. Dry weight was determined after oven-drying the samples at $65^{\circ} \mathrm{C}$. Dry samples were pressure-digested in $2 \mathrm{~mL}$ tubes (Eppendorf, Hamburg, Germany) with a 1:1 mixture of nitric acid (Suprapure, Merck, Darmstadt, Germany) and deionized water in an aluminum oven covered with a heated lid at $69^{\circ} \mathrm{C}$ until a clear solution was obtained. All samples were diluted to $2 \mathrm{~mL}$ with deionized water and $\mathrm{Cd}$ concentrations measured in the flame of an atomic absorption spectrophotometer (model Z-8200, Hitachi, Tokyo, Japan). Calibration was achieved using standard metal solutions in $1 \%$ nitric acid. Accuracy of metal measurements of the midgut gland was verified with certified standard reference material (TORT-2, Lobster Hepatopancreas Reference Material for Trace Metals; National Research Council Canada). 


\subsection{Statistical Methods}

Data of qRT PCR and metal analysis were evaluated statistically by means of Sigma Plot 12.5 . For normal-distributed data, the t-test was applied. For data failing equal distribution the Mann-Whitney rank sum test was used. Statistical significance was set at $p \leq 0.05$.

\section{Conclusions}

The metal-binding capabilities of BgwtMT and its natural mutant BgKNMT, as studied in this work, revealed to be very similar in most of the investigated aspects. This is not of much surprise, as they differ by only one single mutation of a non-coordinating amino acid residue. To summarize, the two proteins share the following features: (1) They lack a clear metal-binding preference for any of the three metal ions assayed- $\mathrm{Zn}(\mathrm{II}), \mathrm{Cd}(\mathrm{II})$ or $\mathrm{Cu}(\mathrm{I})$. To this degree, this feature is clearly unprecedented in the world of Gastropoda MTs, even if some other MT isoforms of this sub-family are also characterized by a relatively small, but when compared to BgMT still significant, degree of metal-binding specificity [16,24]. (2) Consequently, the two MT variants of Biomphalaria glabrata (BgwtMT and BgKNMT) presented, in all the cases, mixtures of several differently metallated species. Accordingly we suspect that none of the uniquely metallated species presents a system significantly lower in energy compared to mixed-metal species. Hence, the metal-BgMT species found are almost equivalent in their $\mathrm{Zn}$ - and Cd-BgMT preparations. (3) The CD profiles of both protein variants are very similar when complexed to the same metal ion. (4) There are, however, slight differences in copper-binding between BgwtMT and BgKNMT: the Cu-BgKNMT preparations contain higher nuclearity $(\mathrm{M}=\mathrm{Zn}+\mathrm{Cu})$ and higher copper content than the $\mathrm{Cu}$-BgwtMT samples. (5) These observations can be explained if we consider the previously reported role of Lys and Asn residues for metal-binding preferences of snail MTs [16]: the replacement of a Lys residue (highly present in the MT isoforms with higher Zn- and/or Cd-thionein character) by an Asn residue (abundant in the so-called Cu-thioneins) reduces the $\mathrm{Cd}$ specificity in favor of $\mathrm{Cu}$ specificity. This increase of the $\mathrm{Cu}$-thionein character is however rather limited, which we attribute to the high number of amino acids and Cys content (33 Cys residues among 126 amino acids) that reduces the influence of a single amino acid mutation. (6) The results from qRT-PCR do not show significant $B g M T$ gene upregulation upon induction by $\mathrm{Cd}$ despite a strong accumulation of $\mathrm{Cd}$ in the midgut gland tissue. (7) This agrees well with the ESI-MS results that fail to show a clear metal-binding preference for BgMTs, while at the same time, indicate a high potential for metal replacement. This suggests that $\operatorname{BgMT}(\mathrm{s})$ in living cells may be more important for metal exchange (e.g., replacement of $\mathrm{Zn}^{2+}$ by $\mathrm{Cd}^{2+}$ ) through a constitutively abundant form, rather than for metal sequestration by an MT species that is highly upregulated in presence of a specific metal. (8) A comparison of the Biomphalaria glabrata MTs with the CdMT isoform of Helix pomatia and MTs of the gastropod clade of Hygrophila (to which Biomphalaria glabrata belongs) shows several deviations in primary structure from the classical domain organization of metal-specific gastropod MTs. These include primary sequence aberrations such as deletions, truncations and chain extensions, along with altering combinations of $\alpha$ and $\beta$ domains. (9) Perhaps as a consequence, different ratios of Cys:divalent metal ions seem to be a common feature of Hygrophila MTs compared to the CdMT of Helix pomatia. (10) Thus, it is hypothesized that these structural "degenerations" of Hygrophila MTs from the classical gastropod MT model may contribute to the impairment of their metal-binding specificity and response properties. At the same time, this may clear the way for the activation of alternative detoxification strategies such as metal complexation by low molecular weight ligands.

Acknowledgments: This work was funded by the Tiroler Wissenschaftsfonds (TWF) (Project ref. 214457) granted to Michael Niederwanger, the Austrian Science foundation (FWF) and the Swiss National Science Foundation (Project ref. I 1482-N28 DACH) granted to Reinhard Dallinger and Oliver Zerbe. Authors from both Barcelona universities are members of the 2014SGR-423 Grup de Recerca de la Generalitat de Catalunya, and they are recipients of MINECO-FEDER grants (BIO2015-67358-C2-1-P to SA and RA, and BIO2015-67358-C2-2-P to MC). We thank the Centres Científics i Tecnològics (CCiT) de la Universitat de Barcelona (DNA sequencing) and the 
Servei d'Anàlisi Química (SAQ) de la Universitat Autònoma de Barcelona (ICP-AES, CD, UV-vis, ESI-MS) for allocating instrument time. Experimental support of Sebastian Artime and Mireia Mata is greatly appreciated.

Author Contributions: Reinhard Dallinger was responsible for the project coordination. Michael Niederwanger, Reinhard Dallinger, Oliver Zerbe, Mercè Capdevila and Sílvia Atrian conceived and designed experiments. Mercè Capdevila, Òscar Palacios, Ricard Albalat and Sílvia Atrian analyzed the data and discussed the experimental results. Sara Calatayud and Michael Niederwanger performed the cloning and recombinant synthesis of the analyzed proteins and Òscar Palacios performed their ESI-MS and CD characterization. Òscar Palacios, Mercè Capdevila, Michael Niederwanger, Oliver Zerbe and Reinhard Dallinger were primarily responsible for writing the manuscript. All authors-except Silvia Atrian that passed away in December the 5th, 2016 and is sorely missed-edited and approved the final version of the manuscript.

Conflicts of Interest: The authors declare no conflict of interest.

\section{References}

1. Dallinger, R.; Berger, B.; Hunziker, P.; Kägi, H.R.J. Metallothionein in snail Cd and Cu metabolism. Nature 1997, 143, 831-833. [CrossRef]

2. Palacios, Ò.; Pagani, A.; Pérez-Rafael, S.; Egg, M.; Höckner, M.; Brandstätter, A.; Capdevila, M.; Atrian, S.; Dallinger, R. Shaping mechanisms of metal specificity in a family of metazoan metallothioneins: Evolutionary differentiation of mollusc metallothioneins. BMC Biol. 2011, 9, 4. [CrossRef] [PubMed]

3. Palacios, Ò.; Pérez-Rafael, S.; Pagani, A.; Dallinger, R.; Atrian, S.; Capdevila, M. Cognate and noncognate metal ion coordination in metal-specific metallothioneins: The Helix pomatia system as a model. J. Biol. Inorg. Chem. 2014, 19, 923-935. [CrossRef] [PubMed]

4. Baumann, C.; Beil, A.; Jurt, S.; Niederwanger, M.; Palacios, Ò.; Capdevila, M.; Atrian, S.; Dallinger, R.; Zerbe, O. Structural adaptation of a protein to increased metal stress: NMR structure of a marine snail metallothionein with an additional domain. Angew. Chem. 2017, 56, 4617-4622. [CrossRef] [PubMed]

5. English, T.E.; Storey, K.B. Freezing and anoxia stresses induce expression of metallothionein in the foot muscle and hepatopancreas of the marine gastropod Littorina littorea. J. Exp. Biol. 2003, 206, 2517-2524. [CrossRef] [PubMed]

6. Pedrini-Martha, V.; Niederwanger, M.; Kopp, R.; Schnegg, R.; Dallinger, R. Physiological, diurnal and stress-related variability of cadmium-metallothionein gene expression in land snails. PLoS ONE 2016, 11, e0150442. [CrossRef] [PubMed]

7. Gnatyshyna, L.L.; Fal'fushinskaya, G.I.; Golubev, O.P.; Dallinger, R.; Stoliar, O.B. Role of metallothioneins in adaptation of Lymnaea stagnalis (Mollusca: Pulmonata) to environment pollution. Hydrobiol. J. 2011, 47, 56-66. [CrossRef]

8. Gonçalves, S.F.; Davies, S.K.; Bennett, M.; Raab, A.; Feldmann, J.; Kille, P.; Loureiro, S.; Spurgeon, D.J.; Bundy, J.G. Sub-lethal Cadmium exposure increases phytochelatin concentrations in the aquatic snail Lymnaea stagnalis. Sci. Total Environ. 2016, 568, 1054-1058. [CrossRef]

9. Martínez-Paz, P.; Morales, M.; Sánchez-Argüello, P.; Morcillo, G.; Martínez-Guitarte, J.L. Cadmium in vivo exposure alters stress response and endocrine-related genes in the freshwater snail Physa acuta. New biomarker genes in a new model organism. Environ. Pollut. 2017, 220, 1488-1497. [CrossRef] [PubMed]

10. DeJong, R.J.; Morgan, J.A.T.; Paraense, W.L.; Pointier, J.P.; Amarista, M.; Ayeh-Kumi, P.F.K.; Babiker, A.; Barbosa, C.S.; Brémond, P.; Canese, A.P.; et al. Evolutionary relationships and biogeography of Biomphalaria (Gastropoda: Planorbidae) with implications regarding its role as host of the human bloodfluke, Schistosoma mansoni. Mol. Biol. Evol. 2001, 18, 2225-2239. [CrossRef] [PubMed]

11. Morgan, J.A.T.; Dejong, R.J.; Snyder, S.D.; Mkoji, G.M.; Loker, E.S. Schistosoma mansoni and Biomphalaria: Past history and future trends. Parasitology 2001, 123, S211-S228. [CrossRef] [PubMed]

12. Gryseels, B.; Polman, K.; Clerinx, J.; Kestens, L. Human schistosomiasis. Lancet 2006, 368, 1106-1118. [CrossRef]

13. Niederwanger, M.; Dvorak, M.; Schnegg, R.; Bacher, K.; Bidoli, M.; Dallinger, R. The metallothionein gene of Biomphalaria glabrata: A complex structure with unexpected response patterns. Manuscript in preparation.

14. Espart, A.; Marín, M.; Gil-Moreno, S.; Palacios, Ò.; Amaro, F.; Martín-González, A.; Gutiérrez, J.C.; Capdevila, M.; Atrian, S. Hints for metal-preference protein sequence determinants: Different metal binding features of the five tetrahymena thermophila metallothioneins. Int. J. Biol. Sci. 2015, 11, 456-471. [CrossRef] [PubMed] 
15. Pagani, A.; Villarreal, L.; Capdevila, M.; Atrian, S. The Saccharomyces cerevisiae Crs5 Metallothionein metal-binding abilities and its role in the response to zinc overload. Mol. Microbiol. 2007, 63, 256-269. [CrossRef] [PubMed]

16. Pérez-Rafael, S.; Monteiro, F.; Dallinger, R.; Atrian, S.; Palacios, Ò.; Capdevila, M. Cantareus aspersus metallothionein metal binding abilities: The unspecific CaCd/CuMT isoform provides hints about the metal preference determinants in metallothioneins. Biochim. Biophys. Acta Proteins Proteom. 2014, 1844, 1694-1707. [CrossRef] [PubMed]

17. Höckner, M.; Stefanon, K.; de Vaufleury, A.; Monteiro, F.; Pérez-Rafael, S.; Palacios, Ò.; Capdevila, M.; Atrian, S.; Dallinger, R. Physiological relevance and contribution to metal balance of specific and non-specific metallothionein isoforms in the garden snail, Cantareus aspersus. BioMetals 2011, 24, 1079-1092. [CrossRef] [PubMed]

18. Jörger, K.M.; Stöger, I.; Kano, Y.; Fukuda, H.; Knebelsberger, T.; Schrödl, M. On the origin of Acochlidia and other enigmatic euthyneuran gastropods, with implications for the systematics of Heterobranchia. BMC Evol. Biol. 2010, 10, 323. [CrossRef] [PubMed]

19. Jo, Y.H.; Baek, M.K.; Kang, S.W.; Lee, J.B.; In-Seon, B.; Choi, S.-H.; Chae, S.-H.; Kang, J.-H.; Han, Y.S.; Park, H.-S.; et al. Molecular cloning and expression pattern of metallothionein gene from left-handed shell, Physa acuta. Korean J. Malacol. 2009, 25, 223-230.

20. Niederwanger, M.; Dallinger, R.; Stoliar, O. University of Innsbruck, Austria. Unpublished work, 2013.

21. Dallinger, R.; Wang, Y.; Berger, B.; Mackay, E.A.; Kägi, J.H.R. Spectroscopic characterization of metallothionein from the terrestrial snail, Helix pomatia. Eur. J. Biochem. 2001, 268, 4126-4133. [CrossRef] [PubMed]

22. Capdevila, M.; Cols, N.; Romero-isart, N.; Gonzàlez-Duarte, R.; Atrian, S.; Gonzàlez-Duarte, P. Recombinant synthesis of mouse $\mathrm{Zn}_{3}-\beta$ and $\mathrm{Zn}_{4}-\alpha$ metallothionein 1 domains and characterization of their cadmium (II) binding capacity. Cell. Mol. Life Sci. 1997, 53, 681-688. [CrossRef] [PubMed]

23. Pérez-Rafael, S.; Kurz, A.; Guirola, M.; Capdevila, M.; Palacios, Ò.; Atrian, S. Is MtnE, the fifth Drosophila metallothionein, functionally distinct from the other members of this polymorphic protein family? Metallomics 2012, 4, 342. [CrossRef] [PubMed]

24. Pérez-Rafael, S.; Mezger, A.; Lieb, B.; Dallinger, R.; Capdevila, M.; Palacios, Ò.; Atrian, S. The metal binding abilities of Megathura crenulata metallothionein (McMT) in the frame of Gastropoda MTs. J. Inorg. Biochem. 2012, 108, 84-90. [CrossRef] [PubMed] 